\title{
Effects of Methyl and Halogens in Analgesic Peptide Molecules for Their Potent Agonist Activities at MOR/DOR and Antagonist Activity at NK1R
}

\author{
Aswini Kumar Giri' ${ }^{1}$ C.R. Apostol'1, P. Davis ${ }^{2}$, D. Rankin², G. Molnar ${ }^{2}$, \\ T.W. Vanderah ${ }^{2}$, F. Porreca ${ }^{2}$, and V.J. Hruby ${ }^{1}$ \\ ${ }^{1}$ Departments of Chemistry and Biochemistry, University of Arizona, Tucson, AZ, 75721, USA; \\ ${ }^{2}$ Department of Pharmacology, University of Arizona, Tucson, AZ, 85724, USA
}

\section{Introduction}

Treating pain has been always challenging, especially when it becomes chronic in nature. Current drugs (e.g. opioid drugs) cannot treat this problem effectively. In addition, constant use of these drugs has deadly side effects including drowsiness and mental clouding, nausea and emesis, and constipation [1]. Development of analgesic tolerance and hyperalgesia in many patients as the results of taking these drugs are also a serious concern. Overexpression of substance $\mathrm{P}$ and its receptor has been observed during prolonged pain states. Studies revealed that co-administration of cocktails of drugs containing $\mu / \delta$ opioid agonist and NK1 antagonist can provide better analgesic effects in rat model while reducing side effects [2-4]. Herein, we report design, synthesis and SARs of few multifunctional ligands having $\mu / \delta$ opioid agonist ( $\mu$-preferring) and NK1 antagonist activities. The detail of this study has already been communicated to J. Med. Chem. for publication [5]. We anticipate that these ligands will show better analgesia while reducing the adverse side effects. Our drug design principle is based on overlapping and adjacent pharmacophores (Figure 1) and we considered our previously published $\mu$-selective (binding) ligand TY012 (H-Tyr-D-Ala-Gly-Phe-Pro-Leu-Trp-NH-Bn(3',5'-(CF3)2)) [6].

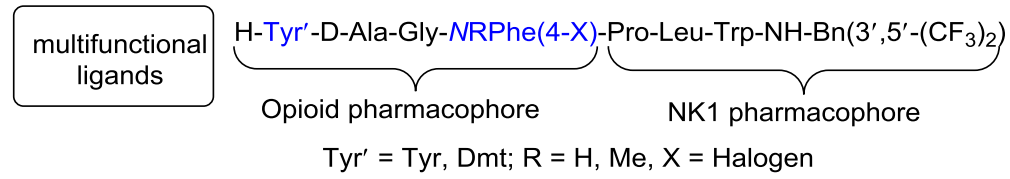

Fig. 1. Design of multifunctional ligands.

\section{Synthesis of the ligands}

Linear peptides [Boc-Tyr( $\left.{ }^{\mathrm{B} u}\right)-(\mathrm{AA})_{\mathrm{n}}$-Pro-Leu-Trp(Boc)-OH] were synthesized using Fmoc/tBu solid phase chemistry on a 2-chlorotrityl resin. The $C$-terminal carboxylic acid was amidated in solution phase. Removal of all protecting groups followed by purification afforded the pure ligands required for biological study. The ligands we designed and synthesized are given in Figure 2.

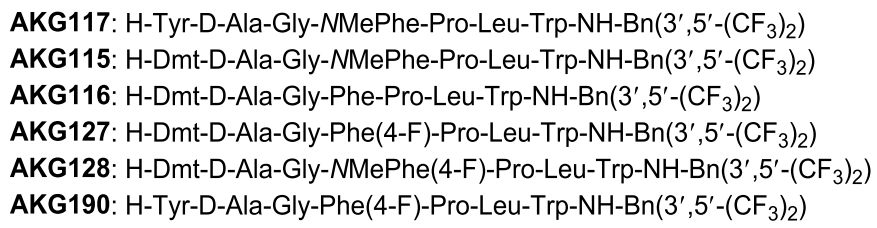

Fig. 2. Structures of our multifunctional ligands.

\section{Results and Discussion}

The present study was designed to synthesized $\mu$-selective ligands while maintaining the antagonist activity at NK1 receptor. To achieve our goal we considered our previously published $\mu$-selective (binding) ligand TY012 [6] and structural modification was conducted in the opioid pharmacophore moiety. We introduced Dmt at the $1^{\text {st }}$ position, and NMe-Phe or halogenated-Phe at the $4^{\text {th }}$ position 
(Figure 2) to achieve our desired selectivity with high potency at all receptors. AKG117 having $N \mathrm{Me}$-Phe at $4^{\text {th }}$ position showed a small increase in $\mu$-agonist activity (Table 1). AKG115 having Dmt at the $1^{\text {st }}$ position and NMe-Phe at the $4^{\text {th }}$ position showed selectivity (both binding and functional) for MOR over DOR (Table 1) while AKG116 containing Dmt at the $1^{\text {st }}$ position and Phe at the $4^{\text {th }}$ position lacked selectivity in binding assay and displayed higher agonist activity at DOR compared to that at MOR (Table 1). AKG127 containing Dmt at the $1^{\text {st }}$ position and Phe(4-F) at the $4^{\text {th }}$ position showed no selectivity in binding assay. However, it showed higher agonist activity for DOR compared to that at MOR (Table 1). AKG128 containing Dmt at the $1^{\text {st }}$ position and $N \mathrm{Me}-\mathrm{Phe}(4-\mathrm{F})$ at the $4^{\text {th }}$ position showed no improvement in selectivity. Replacement of Dmt with Tyr at the $1^{\text {st }}$ position of AKG127 produced the ligand AKG190, which became selective for DOR over MOR in functional assay (Table 1).

Table 1. Binding affinities of the multivalent ligands at MOR, DOR, and NK1R.

\begin{tabular}{ccccccc}
\hline Ligand ID & $K_{i}^{\mu}(n M)$ & $K_{i}^{\delta}(n M)$ & $K_{i}^{h N K 1}(n M)$ & $\begin{array}{l}I C_{5}{ }^{\mu}(n M) \\
(\text { Agonist })\end{array}$ & $\begin{array}{c}I C_{50}{ }^{\delta}(n M) \\
\text { Agonist) }\end{array}$ & $\begin{array}{c}I C_{5} 0^{N K 1}(n M) \\
\text { (Antagonist) }\end{array}$ \\
\hline TY012 & 9.5 & 72 & 0.6 & 350 & 45 & 8.5 \\
AKG117 & 27 & 260 & 3.4 & 230 & 102 & 21 \\
AKG115 & 1 & 5 & 2.2 & 21 & 31 & 9.7 \\
AKG116 & 3 & 1 & 1.4 & 81 & 3.1 & 25 \\
AKG127 & 1 & 1 & 0.9 & 42 & 2 & 5.3 \\
AKG128 & 0.4 & 4 & 2.6 & 77 & 11 & 11 \\
AKG190 & 4 & 7 & 5.6 & 65 & 12 & 5.8 \\
\hline
\end{tabular}

For binding studies, each sample was run three times at each receptor except AKG190 which was run for twice at MOR. For functional activity studies, each sample was run four times.

We have designed and synthesized novel multifunctional ligands, which are highly potent at the receptors of our interest with desired activities. Ligand AKG115 has shown selectivity at MOR over DOR in binding as well as in functional assays. In vivo study with this ligand is now in progress to evaluate its analgesic activity.

\section{Acknowledgments}

We thank US Public Health Service, National Institute of Health (NIH) for supporting this research (Grant No.: 2P01 DA 006284 \& R01 DA 013449). An international patent application has been filed with this discovery.

\section{References}

1. Giri, A.K., Hruby, V.J. Expert Opinion on Investigational Drugs 23, 227-241 (2014), http://dx.doi.org/10.1517/13543784.2014.856879

2. Misterek, K., Maszczynska, I., Dorociak, A.; Gumulka, S.W., Carr, D.B., Szyfelbein, S.K. Lipkowski, A.W. Life Sci. 54, 939-944 (1994), http://dx.doi.org/10.1016/0024-3205(94)00494-3

3. Powell, K.J., Quirion, R., Jhamandas, K. Eur. J. Neurosci. 18, 1572-1583 (2003), http://dx.doi.org/10.1046/j.1460-9568.2003.02887.x

4. Ripley, T.L., Gadd, C.A., De Felipe, C., Hunt, S.P., Stephens, P.H. Neuropharmacology 43, 1258-1268 (2002), http://dx.doi.org/10.1016/S0028-3908(02)00295-2

5. Giri, A.K., Apostol, C.R., Davis, P., Rankin, D., Molnar, G., Olson, K.M., Wang, Y., Forte, B.L., LargentMilnes, T.M., Vanderah, T.W., Porreca, F., Hruby, V.J. J. Med. Chem. (communicated).

6. Yamamoto, T. Nair, P., Vagner, J., Largent-Milnes, T.M., Davis, P., Ma, S.-w., Navratilova, E., Moye, S., Tumati, S., Lai, J., Yamamura, H.I., Vanderah, T.W., Porreca, F., Hruby, V.J. J. Med. Chem. 51, 1369-1376 (2008), http://dx.doi.org/10.1021/jm070332f 